Campos Neutrais - Revista Latino-Americana de Relações Internacionais Vol. 2, No 1, Janeiro- Abril de 2020. Santa Vitória do Palmar - RS.

\title{
Decolonialidade e futebol: a quebra da lógica periferia-centro
}

\author{
Juliano Oliveira Pizarro* \\ Carmen Silvia de Moraes Rial** \\ Luiz Carlos Rigo ${ }^{* * *}$
}

\begin{abstract}
Resumo: Com o "descobrimento" do continente americano, teve início o que muitos chamam de sistema-mundo moderno. Mesmo após a independência dos países, que eram colônias de grandes potências europeias, a colonização não teve fim. Ela continua, até hoje, principalmente através do chamado sistema neoliberal. Contudo, a globalização não apenas manteve a lógica da colonialidade econômica, mas também no aspecto cultural. Assim, se criou os estudos subalternos, tendo em vista criar teorias do sul global para o sul, fazendo necessário um processo de decolonização. O presente trabalho versa sobre como o futebol, considerado o esporte mais praticado do mundo, apesar de mostrar as facetas mais preconceituosas da sociedade e da lógica colonial, é um instrumento extremamente importante no processo decolonial, fazendo com que se quebre a lógica periferiacentro tradicional do atual sistema-mundo.
\end{abstract}

Palavras-chave: Futebol, Decolonialidade, América do Sul.

\section{Decolonialityand football: a break in theperiphery-center logic}

Abstract: Withthe "discovery" ofthe American continent, what many call the modern worldsystem began. Even after the Independence of the countries that were colonies of great Europe an powers, colonization was never ending. It continues today, mainly through the so-called neoliberal system. However, globalization has no tonly maintained the lógico feconomic coloniality, but also in the cultural aspect. Thus, subaltern studies were created, with a view to creating theories from the global south to the south, making a process of decolonization necessary. The present work deals withhow soccer, considered as them ost practiced sport in the world, despites how ing the most prejudiced facets of society and the colonial logic, is an extremely important instrument in the decolonial process, causing the break of the traditional periphery-center logic of the current worldsystem.

Keywords: Football, Decoloniality, South America.

\section{Introdução}

Em um mundo globalizado, raízes do colonialismo, de alguns séculos, ainda permanecem vivas na sociedade. Mesmo após o processo de descolonização de países ao redor do mundo, as marcas da colonização existem e ainda se reproduzem. Neste âmbito, surge a necessidade de se estudar os fenômenos do pós-colonialismo, escola de pensamento que visa entender como o colonialismo se perpetua até os dias de hoje, nas mais diversas sociedades.

Não se trata, apenas, do ponto de vista político, mas também do ponto de vista econômico, cultural e, consequentemente, do epistemológico, de forma intrínseca, chamado de colonialismo interno. (GONZALÉZ CASANOVA, 2007). A partir disso, também surgem os estudos decoloniais, buscando acabar com essa lógica, principalmente a

\footnotetext{
* Doutorando pelo Programa de Pós-Graduação Interdisciplinar em Ciências Humanas da Universidade Federal de Santa Catarina

${ }^{* * *}$ Professora do Programa de Pós-Graduação Interdisciplinar em Ciências Humanas da Universidade Federal de Santa Catarina.

**** Professor do Programa de Pós-Graduação em Educação Física da Universidade Federal de Pelotas.
} 
Campos Neutrais - Revista Latino-Americana de Relações Internacionais Vol. 2, No 1, Janeiro- Abril de 2020. Santa Vitória do Palmar - RS.

do pensamento eurocentrista, que visa quebrar essa epistemologia do conhecimento, criada e reproduzida, ao longo dos séculos. (QUIJANO, 2005).

Contudo, se busca mecanismos, dentro da modernidade, que possuam um potencial de contribuir nesse processo de decolonialidade. O esporte é um desses mecanismos, principalmente o futebol, considerado o mais praticado do mundo. Possui esse caráter "democrático", tendo em vista ser praticado em diversos lugares do mundo e assistido por pessoas de todas as "raças e classes sociais".

Visando um entendimento epistemológico do futebol, ficam evidentes os problemas que atingem, diariamente, a sociedade em partidas de futebol, tais como violência, racismo e xenofobia, acabando, por diversas oportunidades, reproduzindo o colonialismo, sob muitas vertentes. Através de uma revisão bibliográfica e da análise de dados, com o intuito de compreender a lógica da modernidade e da colonialidade no futebol, o trabalho almeja mostrar, também, a importância desse esporte, sob o ponto de vista decolonial, exatamente por ajudar a combater os problemas citados e, ainda, por quebrar a tradicional divisão periferia-centro, do sistema-mundo moderno, colocando países sul-americanos como centro e grandes potências imperialistas neoliberais como periféricos.

\section{Pós-Colonialismo e o sistema-mundo moderno}

\subsection{Aspectos gerais dos estudos decoloniais e pós-coloniais}

Através de um breve diálogo com autores que trabalham com a temática, se busca trazer os aspectos gerais dos estudos subalternos, buscando entender o pensamento teórico do pós-colonialismo e, também, dos autores que trabalham com os estudos decoloniais. Há um interessante debate, que, de certa forma, ainda não chegou ao mainstream, entre decoloniais e pós-coloniais, com grandes autores do chamado "sul global”, principalmente latino-americanos.

Nesse primeiro capítulo, se tem o intuito de abordar essa temática, através de seus pontos principais, mostrando a importância que o grupo modernidade/colonialidade possui na elaboração de teorias do sul para o sul. Assim, além de trazer à tona essa vertente teórica, se busca dar uma base ao leitor para entender, posteriormente, a importância direta e indireta que o futebol sul-americano possui para a cultura e a política de países da periferia global.

Primeiramente, cabe salientar que o conceito de decolonialidade é, muitas vezes, confundido com os conceitos de descolonização e pós-colonialismo. No entanto, os 
Campos Neutrais - Revista Latino-Americana de Relações Internacionais Vol. 2, No 1, Janeiro- Abril de 2020. Santa Vitória do Palmar - RS.

teóricos decoloniais fizeram distinções claras.

\subsubsection{Pensamento pós-colonial}

Como epistemologia, ética e política, o campo do pós-colonialismo aborda a política do conhecimento, através dos fatos que constituem a identidade pós-colonial, após a descolonização de uma nação. Alguns fatores derivam de uma lógica colonial, mas, principalmente, a geração de conhecimento cultural do colonizador sobre os povos colonizados, e o modo de aplicação desse conhecimento cultural para subjugar um povo não-europeu, em uma colônia de determinado país europeu, em que, após a invasão, foi realizada por meio das identidades culturais de "colonizador" e "colonizado".

Nesse sentido, é importante o entendimento sobre colonialismo interno de Pablo González Casanova (2007):

A definição do colonialismo interno está originalmente ligada a fenômenos de conquista, em que as populações de nativos não são exterminadas e formam parte, primeiro do Estado colonizador e depois do Estado que adquire uma independência formal, ou que inicia um processo de libertação, de transição para o socialismo, ou de recolonização e regresso ao capitalismo neoliberal. Os povos, minorias ou nações colonizadas pelo Estado-nação sofrem condições semelhantes às que os caracterizam no colonialismo e no neocolonialismo em nível internacional: 1) habitam em um território sem governo próprio; 2) encontram-se em situação de desigualdade frente às elites das etnias dominantes e das classes que as integram; 3) sua administração e responsabilidade jurídico-política concernem às etnias dominantes, às burguesias e oligarquias do governo central ou aos aliados e subordinados do mesmo; 4) seus habitantes não participam dos mais altos cargos políticos e militares do governo central, salvo em condição de "assimilados"; 5) os direitos de seus habitantes, sua situação econômica, política social e cultural são regulados e impostos pelo governo central; 6) em geral os colonizados no interior de um Estado-nação pertencem a uma "raça" distinta da que domina o governo nacional e que é considerada "inferior", ou ao cabo convertida em um símbolo "libertador" que forma parte da demagogia estatal; 7) a maioria dos colonizados pertence a uma cultura distinta e não fala a língua "nacional".

Pós-colonialismo é um conjunto de teorias que analisam os efeitos políticos, filosóficos, artísticos e literários, deixados pelo colonialismo, nos países colonizados. A teoria pós-colonial tornou-se conhecida, nos anos 1970, a partir do livro "Orientalismo", de Edward Said, tido como a obra fundadora, descrevendo a relação social com a qual a Europa Ocidental, intelectualmente, dividiu o mundo em "Ocidente" e "Oriente". O autor desenvolveu as denotações e conotações do termo "orientalismo", principalmente como a 
Campos Neutrais - Revista Latino-Americana de Relações Internacionais Vol. 2, No 1, Janeiro- Abril de 2020. Santa Vitória do Palmar - RS.

figura do "outro". (CASTRO-GÓMEZ, 2005). Mas, ainda há outros autores que podemos considerar pioneiros, tais como Frantz Fanon (1965) em "Os condenados da terra", em que o psiquiatra analisa, clinicamente, a natureza do colonialismo, como algo essencialmente destrutivo, pois seus efeitos sociais - a imposição de uma identidade colonial subjugada são prejudiciais à saúde mental dos povos de cor, que foram subjugados em colônias.

Ao estabelecer a definição pós-colonial do termo subalterno, a filósofa e teórica Gayatri Spivak, autora da famosa obra "Pode o subalterno falar?" (2010), fala que povos subalternos nunca podem expressar suas formas de conhecimento (pensamento, raciocínio, linguagem) e, em vez disso, devem estar em conformidade com as formas ocidentais de conhecimento do mundo. Ainda, em "Provincializing Europe", Dipesh Chakrabarty (2010) traçou a história subalterna da luta pela independência indiana, e, rebatendo o pensamento eurocentrista, propôs que a Europa Ocidental simplesmente fosse considerada culturalmente igual às outras culturas do mundo. (CASTRO-GÓMEZ, 2005).

\subsubsection{Pensamento decolonial}

Decolonialidade não é apenas o processo de descolonização de um povo. Decolonialidade é um termo usado, principalmente, por um movimento latino-americano emergente, que tem como foco entender a modernidade no contexto de uma forma de teoria crítica, aplicada a estudos étnicos. Ele foi descrito por Walter Mignolo (2005) como opções analíticas e práticas que confrontam e desvinculam a matriz colonial de poder. Pode ser contrastado com a colonialidade, conceituada como a lógica subjacente da fundação e desdobramento da civilização ocidental desde a Renascença até hoje, referida como a matriz colonial de poder ou de colonialidade do poder.

A colonização formal e explícita terminou com a descolonização da maioria dos países do continente americano, durante o século XIX, e com a descolonização de grande parte do sul global no final do século XX. Apesar disso, surgiram novas formas de colonização, através da sistemática neoliberal, imperialista e globalizada, a qual perpetuou as desigualdades.

A matriz colonial de energia é produzida à discriminação social, eventualmente, codificada como "racial", "étnica", "antropológica" ou "nacional", de acordo com os contextos históricos, sociais e geográficas específicas. (QUIJANO, 1992). A decolonilidade é um confronto contínuo de desvincular a ótica eurocentrista, ou seja, quebrar a ideia de que a história da civilização humana tem sido a história europeia, acabando com as diferenças do sujeito europeu e não-europeu. 
Para Mignolo (2010), o pensamento decolonial tem sido chamado de uma forma de "desobediência e reconstrução epistêmica". É um meio de eliminar a tendência provincial para fingir que os modos de pensar da Europa Ocidental são, de fato, universais, buscando a libertação social de todo o poder organizado da desigualdade, discriminação, exploração e dominação.

Decolonizar é colocar em xeque, se perguntar e problematizar todo e qualquer pensamento com base no eurocentrismo. A história do mundo baseado na história da Europa, enquanto a lógica da civilização ocidental. Decolonialidade é uma resposta à relação de dominação direta, política, social e cultural estabelecida pelos europeus. (QUIJANO, 2005). Isso significa que decolonialidade refere-se a abordagens analíticas, epistemológicas, além de práticas socioeconômicas e políticas, que se opõem aos pilares da civilização ocidental: colonialidade e modernidade.

Neste sentido, Walter Mignolo (2011) diz que decolonialidade é o reconhecimento e a implementação de uma razão subalterna. Cita que, em suas aplicações práticas, tais como movimentos indígenas autônomos (ex: Zapatistas), possuem um autogoverno, em razão da omissão dos governos modernos de direita ou de esquerda, fazendo com que os movimentos sociais busquem o que ele denomina de "nova humanidade".

\subsection{Sistema-mundo moderno de Wallerstein}

Teoria do sistema-mundo é uma abordagem que salienta que o mundo (não os Estados-nação) deveria ser a unidade principal de análise social. Sistema-mundo refere-se à inter-regional e transnacional divisão do trabalho, que divide o mundo em países centrais, os países semiperiféricos e os da periferia. Os países centrais concentram maior capital de produção e técnicas, e o resto do mundo focaliza na baixa qualificação, produção e extração de matérias-primas, reforçando, constantemente, o domínio dos países centrais.

No entanto, o sistema é dinâmico, em parte, como resultado das revoluções em tecnologia de transporte, e os estados individuais podem ganhar ou perder o status de núcleo (semiperiferia, periferia), ao longo do tempo. Como exemplo, se constatou que, por um determinado tempo, alguns países foram hegemônicos, durante os últimos séculos, mas como o sistema-mundo se estendeu geograficamente, intensificando sua atividade economicamente, esse status passou da Holanda para o Reino Unido e, mais recentemente, para os Estados Unidos. Enrique Dussel (2011) traz uma contribuição para o debate, mas, sob a ótica epistemológica eurocentrista: 
A "hipótese" de um Sistema-Mundo surgiu como contrapartida de um primeiro eurocentrismo, que pensava que a Europa, a partir de suas supostas origens medievais gregas e latinas, produzia "de dentro" os valores, os sistemas instrumentais (posições de Hegel, Marx, Weber ou Sombart) que se tornou universal nos últimos cinco séculos, na época da Modernidade. Esta posição eurocêntrica, que se formulou pela primeira vez no final do século XVIII, com os "iluministas" franceses e ingleses, e os "românticos" alemães, reinterpretou toda a História Mundial, projetando a Europa no passado e tentando demonstrar (demonstração que deu frutos para a Europa nos últimos dois séculos) que tudo foi preparado na História Universal para que esta Europa fosse "o fim e o centro da História Mundial" - como disse Hegel. Foi com os "enciclopedistas" que a distorção da história começou pela primeira vez (L'Esprit des Lois de Montesquieu é um bom exemplo), mas também com os "ilustrados" ingleses, e na Alemanha com Kant, e finalmente com Hegel, para quem o "Oriente" era a "infância (Kindheit)" da humanidade, o lugar do despotismo e da não-liberdade, de onde mais tarde o Espíritu (o Volksgeist) ascenderá ao Ocidente, como em um caminho para a plenitude realização da Liberdade e da Civilização. A Europa sempre teria sido escolhida pelo Destino para ser o significado final da História Universal. (Tradução nossa) ${ }^{1}$

Immanuel Wallerstein desenvolveu a versão mais conhecida da análise de sistemasmundo, começando na década de 1970. Para o autor Wallerstein (2005), a ascensão do capitalismo foi resultado da longa crise do feudalismo, onde a Europa utilizou seu controle sobre a maior parte do mundo, conquistando vantagens econômicas, presidindo o desenvolvimento e propagando a industrialização e o capitalismo, que de forma indireta, resultou em um desenvolvimento desigual.

Wallerstein (2005) afirma que os sistemas-mundo é, sobretudo, um modo de análise que visa transcender as estruturas do conhecimento herdado, do século XIX, tendo a ideia de que a análise do sistema-mundo é um movimento epistemológico. Sua visão é a de que se deve inventar uma nova linguagem, transcendendo as ilusões sociais, econômicas e políticas impostas pelos colonizadores, através da alienação de mundos biofísicos. Numa análise desses sistemas-mundo, Restrepo e Rojas (2010) dizem que:

Como resultado da consolidação do sistema-mundo moderno, a Europa

\footnotetext{
${ }^{1}$ La "hipótesis" de un World-System surgió como contrapartida de un primer eurocentrismo, que pensó que Europa, desde sus pretendidos orígenes griegos y medievales latino, produjo "desde-dentro" los valores, los sistemas instrumentales (posiciones de Hegel, Marx, Weber o Sombart) que se universalizaron en los últimos cinco siglos, en el tiempo de la Modernidad. Esta posición eurocéntrica que se formula por primera vez a finales del siglo XVIII, con la "Ilustración" francesa e inglesa, y los "románticos" alemanes, reinterpretó la Historia Mundial toda entera, proyectando a Europa hacia el pasado, e intentando demostrar (demostración que ha rendido frutos a Europa en los dos últimos siglos) que todo había sido preparado en la Historia Universal para que dicha Europa fuera "el fin y el centro de la Historia Mundial" -al decir de Hegel. Fue con los "Enciclopedistas" que comienza por primera vez la distorsión de la historia (L'Esprit des Lois de Montesquieu es un buen ejemplo), pero igualmente con los "ilustrados" ingleses, y en Alemania con Kant, y finalmente con Hegel, para el que el "Oriente" era la "niñez (Kindheit)" de la humanidad, el lugar del despotismo y la no-libertad, desde donde posteriormente el Espíritu (el Volksgeist) remontará hacia el Oeste, como en un camino hacia la plena realización de la Libertad y la Civilización. Europa habría sido desde siempre elegida por el Destino para ser el sentido final de la Historia Universal.
} 
passou por grandes transformações. Talvez o de maior incidência tenha a ver com a legitimação de um sistema altamente desigual, tanto dentro das sociedades europeias quanto nas colônias estabelecidas do outro lado do Atlântico, na nascente América. O lugar que a Europa conquistou no contexto do sistema nascente levou-a a ser o centro de poder no contexto mundial nos séculos seguintes. (Tradução nossa) ${ }^{2}$

Nesse sentido, através do entendimento da lógica do sistema-mundo moderno, fica clara a necessidade de decolonizar o pensamento brasileiro e latino-americano, exatamente para mudar essa lógica e quebrar paradigmas ainda intrínsecos.

\section{Futebol: modernidade, preconceito e decolonialidade}

A busca de um processo de decolonização pelos países periféricos é um processo que exige uma decolonização interna e intersubjetiva. Em razão disso, buscam-se mecanismos que podem ser importantes nesse processo, e o esporte surge com um grande potencial decolonial, o qual quebra muitas barreiras do pensamento eurocentrista e colonial. Considerado como o esporte mais praticado no mundo, possui uma penetração nas altas classes sociais das grandes potências, assim como nas camadas mais baixas da população de países pobres, os mais atingidos pelas barbáries decorrentes do atual sistema neoliberal.

No mundo globalizado, o futebol profissional é tratado como um negócio altamente lucrativo, imerso na modernidade do sistema-mundo. Contudo, apesar de ser um esporte democrático em sua essência, sendo praticado por pessoas no mundo inteiro, possuindo mais países com federações nacionais ligadas ao órgão máximo do futebol do que nações ligadas à Organização das Nações Unidas, traz à tona uma série de problemáticas.

Um dos maiores problemas enfrentados ao redor do mundo é o racismo sofrido por jogadores negros no futebol mundial, não se restringindo apenas à Europa, mas em todo planeta. Há, ainda, casos de violência e de xenofobia com jogadores e torcedores dos mais diferentes lugares. Nesse sentido, o entendimento das causas dessas questões é fundamental e, a partir disso, deve-se tentar entender como o futebol pode ser útil no processo de decolonização dos países periféricos.

\subsection{Modernidade/Colonialidade}

Para estudar o futebol moderno, é importante compreender a lógica da modernidade

\footnotetext{
${ }^{2}$ Como resultado de la consolidación del sistema-mundo moderno, Europa vivió grandes transformaciones. Tal vez la de mayor incidencia tiene que ver con la legitimación de un sistema altamente desigual, tanto al interior de las sociedades europeas, como en las colonias establecidas al otro lado del Atlántico, en la naciente América. El lugar que ganó Europa en el contexto del sistema naciente la llevó a ser el centro del poder en el contexto mundial durante los siguientes siglos.
} 
Campos Neutrais - Revista Latino-Americana de Relações Internacionais Vol. 2, No 1, Janeiro- Abril de 2020. Santa Vitória do Palmar - RS.

e da colonialidade. Também chamada de colonialidade do poder, trata-se de uma teoria da inter-relação entre as práticas e os legados do colonialismo europeu, tanto em ordens sociais, como em formas de conhecimento. A teoria descreve o legado vivo de colonialismo nas sociedades contemporâneas, na forma de discriminação social, que sobreviveu ao colonialismo formal e tornou-se integrado em sucessivas ordens sociais.

O conceito identifica as ordens hierárquicas raciais, políticas e sociais impostas pelo colonialismo europeu na América Latina, impondo valores para certos povos e privando direitos a outros. Quijano (1992) argumenta que a estrutura colonial de poder resultou em um sistema de castas, classificando os espanhóis no topo e os povos que eles conquistaram, devido às suas diferentes características fenotípicas, em uma cultura que se presumia inferior.

Esta classificação resultou em um discurso categórico e discriminatório, que se refletiu na estrutura social e econômica da colônia, e que continua a refletir-se na estrutura das sociedades pós-coloniais modernas. O conceito também foi expandido por Ramón Grosfoguel, Walter Mignolo, Nelson Maldonado-Torres, dentre outros. A partir de então, por volta do ano 2000, surgiu o grupo conhecido como "Modernidade/Colonialidade", o qual é composto pelos autores citados, juntamente com outros grandes autores (em sua maioria, latino-americanos), com o intuito de estudar e debater essa temática, visando formar novas teorias do sul-global para o sul-global.

No manifesto inaugural do grupo (1998), consta que:

O que norteia o nosso trabalho é, principalmente, o consenso quanto à necessidade de construção de um mundo democrático. Acreditamos que o caráter ético e epistemológico desse consenso e o destino dos processos de democratização na América Latina estão vinculados de tal forma que impõem novos desafios e demandas ao nosso trabalho como acadêmicos e educadores. Isso implica, por um lado, uma maior sensibilidade à complexidade das diferenças sociais e, por outro, a criação de uma plataforma plural, ainda que limitada, de pesquisa e discussão em que todos possam participar. As configurações tradicionais da democracia e do Estado-nação têm impedido que as classes sociais subalternas participem ativamente dos processos políticos e da constituição do conhecimento acadêmico, sem reconhecer suas contribuições potenciais como capital humano (exceto para explorá-lo). (Tradução nossa) ${ }^{3}$

\footnotetext{
${ }^{3}$ Lo que establece las pautas de nuestro trabajo es, principalmente, el consenso respecto a la necesidad de construir un mundo democrático. Creemos que la naturaleza ética y epistemológica de este consenso y el destino de los procesos de democratización en Latinoamérica están unidos de tal forma, que imponen nuevos retos y exigencias a nuestra labor como académicos y educadores. Esto implica, por un lado, una mayor sensibilidad frente a la complejidad de las diferencias sociales y, por el otro, la creación de una plataforma plural, aunque limitada, de investigación y discusión en la que todos puedan tomar parte. Las configuraciones tradicionales de la democracia y el estado-nación han impedido que las clases sociales subalternas tomen parte activa en los procesos políticos y en la constitución del saber académico, sin reconocer sus contribuciones potenciales como capital humano (excepto para explotarlo).
} 
Campos Neutrais - Revista Latino-Americana de Relações Internacionais Vol. 2, No 1, Janeiro- Abril de 2020. Santa Vitória do Palmar - RS.

É um movimento, basicamente, formado por pensadores e intelectuais latinoamericanos, sendo estudadas suas teorias em diversas universidades ao redor do mundo. Ballestrin (2013) aponta que:

O Grupo Modernidade/Colonialidade possui méritos importantes de serem destacados. Trata-se de um trabalho reflexivo coletivo, transdisciplinar e engajado, que ao mesmo tempo em que oferece novas leituras analíticas, é capaz de pensar em termos propositivos e programáticos. Com isso, projeta sua importância para o mundo e para a América Latina, renovando utopia e crítica nas ciências sociais latinoamericanas. Sua proposta é ao mesmo tempo provocativa e desconfortável, dado o tom de indeferimento radical às conquistas do passado via liberalismo e marxismo e às influências de escolas que o permitiram, afinal, existir. Essa sensação deve-se ao fato de que seus autores dialogam de uma maneira seletiva com os nomes clássicos modernos e contemporâneos - das ciências sociais e da filosofia, geralmente, apontando suas deficiências na cobrança de um elemento (colonial) sobre o qual o próprio contexto demandava iluminação. Entretanto, uma de suas estratégias consiste mesmo na revisão do que é considerado clássico.

Tendo como base as ideias pós-coloniais e decoloniais, conhecendo o grupo "Modernidade/Colonialidade" e sabendo de suas teorias, ficam claros os desafios que possuem. Desafios oriundos das raízes coloniais aparecem de forma constante na sociedade. Um dos locais em que se observa, com frequência, os acontecimentos desse tipo de problema, como preconceito racial, xenofobia, violência, dentre outros, são em estádios de futebol. São lugares onde os ânimos se acirram e a capacidade de entendimento, de compreensão moral e ética, por vezes, desaparecem.

\subsection{Preconceito no futebol: xenofobia e racismo}

Mesmo com a criação de um grupo para entender a lógica da modernidade/colonialidade, ela ainda está muito enraizada na cultura das sociedades, tanto periféricas como do centro. No futebol, por ser um esporte que envolve fortes questões ideológicas, fanatismo e paixão, há muitos casos em que esse pensamento aparece de forma clara.

Tanto em partidas internacionais, como em jogos de campeonatos nacionais, ocorrem diversos problemas, entre os mais graves os casos de racismo e de xenofobia. Ainda, a partir de acontecimentos dessa índole, que mostram ainda o pensamento colonial da sua forma mais primitiva e preconceituosa, acabam gerando atos de violência, com finais trágicos em certos casos. 
Campos Neutrais - Revista Latino-Americana de Relações Internacionais Vol. 2, No 1, Janeiro- Abril de 2020. Santa Vitória do Palmar - RS.

\subsubsection{Xenofobia e violência no futebol}

O preconceito é algo que atravessa os anos no futebol, sendo o racismo um de seus principais. Muitos casos foram registrados ao longo do tempo. Há registro de casos em diversos lugares do mundo, principalmente na América Latina e na Europa, envolvendo atletas e torcedores de todas as partes.

Em relação a sua origem, Eduardo Restrepo e Axel Rojas (2010) dizem que:

O racismo é inerente à experiência colonial. Inicialmente é articulado como racismo biológico, como 'racismo vulgar'; depois, com a mudança das condições de dominação colonial, surge um racismo cultural, mais elaborado. Esta distinção apela a um deslocamento do biológico para o modo de existência: "O racismo vulgar, primitivo, simplista tentou encontrar no biológico, visto que as Escrituras se revelaram insuficientes, a base material de sua doutrina" (Fanon 1963: 39). Porém, "esse racismo que quer ser racial, individual, determinado, genotípico e fenotípico, se transforma em racismo cultural" (1963: 39). Ou seja, "O objeto do racismo deixa de ser o homem particular e uma certa forma de existir" (1963: 40). Seja como racismo vulgar ou cultural, o racismo não é um fenômeno de indivíduos com desvios morais, que em algum momento seria superado, mas é constitutivo das formações sociais coloniais tanto do lado do país colonizado quanto do colonizador (Tradução nossa) ${ }^{4}$

Alguns desses atos estão entre os próprios sul-americanos. Citemos o caso do torneio Clausura, de 2009, na Argentina, no qual a Federação Boliviana protestou ante à Conmebol (Confederação Sul-Americana de Futebol) contra atos xenófobos, da torcida do Independiente, que usou bandeiras da Bolívia e do Paraguai para ofender o adversário Boca Juniors. (IG, 2009).

No estádio, um grupo de torcedores do Independiente estendeu bandeiras da Bolívia e do Paraguai, tendo em vista provocar a torcida adversária. Isso se deu em virtude do alto número de imigrantes bolivianos e paraguaios, que vivem na Argentina. Grande parte se concentra em regiões menos favorecidas, de Buenos Aires e algumas perto do Estádio do Boca Juniors, e em decorrência disso, muitos viraram torcedores da equipe do bairro de La Boca.

O presidente da Federação Boliviana declarou que a atitude não só afeta a

\footnotetext{
${ }^{4}$ El racismo es consustancial a la experiencia colonial. Inicialmente se articula como racismo biológico, como 'racismo vulgar'; posteriormente con el cambio de las condiciones de dominación colonial emerge un racismo cultural, uno más elaborado. Esta distinción apela a un desplazamiento de lo biológico al modo de existencia: "El racismo vulgar, primitivo, simplista, pretendía encontrar en lo biológico, ya que las Escrituras se habían revelado insuficientes, la base material de su doctrina" (Fanon1963: 39). No obstante, "Este racismo que se quiere racial, individual, determinado, genotípico y fenotípico, se transforma en racismo cultural" (1963: 39). Es decir, que "El objeto del racismo deja de ser el hombre particular y sí una cierta manera de existir" (1963: 40).Ya sea como racismo vulgar o cultural, el racismo no es un fenómeno de individuos con desviaciones morales, que en algún momento sería superado, sino que es constitutivo de las formaciones sociales coloniales tanto del lado del país colonizado como del colonizador
} 
Campos Neutrais - Revista Latino-Americana de Relações Internacionais Vol. 2, No 1, Janeiro- Abril de 2020. Santa Vitória do Palmar - RS.

dignidade boliviana, como também a paraguaia. Ainda, foi questionada a postura da arbitragem, que permitiu a continuidade do jogo ao invés de pedir que se recolhessem as bandeiras. Contudo, apesar desse fato, pouco tempo depois, os atos de xenofobia se repetiram na Argentina, novamente pelo fato da equipe do Boca Juniors ter muitos torcedores bolivianos e paraguaios. Na vez seguinte, os responsáveis foram os "hinchas" do Vélez Sarsfield. No Estádio José Amalfitani, o triste episódio, envolvendo uma torcida sul-americana, ocorreu em uma partida, na qual apenas havia torcedores do time da casa. Membros do público do Vélez entoaram um coro preconceituoso, ironizando a origem imigracional de muitos torcedores do Boca Juniors. A canção preconceituosa rapidamente repercutiu no gramado. Porém, dessa vez, o árbitro paralisou o confronto, até que cessasse o ato xenofóbico. (MSN, 2014).

Devido aos recorrentes casos de xenofobia na Argentina, na Copa América de 2011, que foi disputada na Argentina, o Fundo das Nações Unidas para a Infância (UNICEF) promoveu uma campanha no país-sede, para evitar casos de discriminação no torneio. A Copa América, tradicionalmente, é marcada por provocações, que vão além das rivalidades esportivas. Além de questões de imigração, há também rivalidades fronteiriças e cânticos que contêm apelidos de cunho racista e homofóbico, questões que viraram algo até corriqueiro em estádios sul-americanos. Em razão disso, a campanha do UNICEF surgiu, algo que é comum em competições da FIFA e da UEFA. (FOLHA, 2011).

Contudo, esse tipo de atos discriminatórios é antigo e não acontece apenas na América do Sul. Rivalidades históricas, muitas vezes, foram refletidas em atos de violências, em partidas de futebol. A maior e mais trágica de todas ficou conhecida como Tragédia de Heysel. Ocorreu na Bélgica, no dia 29 de maio de 1985, quando estava para ser disputada a final da Taça dos Campeões Europeus, entre Liverpool da Inglaterra e Juventus da Itália (LANCENET, 2013):

\begin{abstract}
A tragédia de Heysel, na Bélgica, teve um efeito devastador sobre o futebol inglês. Em 1985, durante a final da Liga dos Campeões da Europa, os poucos policiais, além das grades que separavam seguidores de Liverpool e Juventus, não foram suficientes para evitar um confronto entre as duas torcidas. Foram 38 mortos e 454 feridos (270 hospitalizados). Os torcedores dos Reds levaram a culpa pelo massacre. Como consequência, os clubes do país foram suspensos de competições internacionais durante cinco anos. O Liverpool acabou pagando seis. A primeira-ministra Margaret Thatcher apoiou a decisão da Uefa.
\end{abstract}

Tendo em vista que a expectativa em relação ao jogo era grande (e, logicamente, 
Campos Neutrais - Revista Latino-Americana de Relações Internacionais Vol. 2, No 1, Janeiro- Abril de 2020. Santa Vitória do Palmar - RS.

por fatores financeiros) a UEFA decidiu que partida se realizaria, mesmo após o ocorrido. A partida terminou em 1 a 0 para a Juventus. Logo após seu término, 14 jogadores do Liverpool foram presos, por participarem da confusão. Os hooligans ingleses foram responsabilizados pelo incidente, sendo as reações dos ingleses de reprovação pelos atos violentos dos torcedores do Liverpool.

Outro caso parecido, porém, sem mortes, envolveu um forte contexto político, na partida da Eurocopa, de 2012, entre Polônia e Rússia, resultando em mais de 180 pessoas presas e 15 feridas, e sendo denominada como a "Batalha de Varsóvia". O confronto iniciou após milhares de russos marcharem pela capital polonesa em direção ao estádio, comemorando o Dia da Rússia. Ocorre que se criou um ambiente hostil e de provocações, onde iniciaram-se os confrontos, após russos exibirem símbolos soviéticos, exaltando os tempos de domínio na Polônia. (TERRA, 2012a).

Ainda, símbolos e atos xenofóbicos trazem à tona, muitas vezes, ideologias fascistas, que claramente aparecem em algumas partidas de futebol. Um caso complicado acontece em Amsterdam, onde o Ajax, clube da cidade, possui ligação com judeus. Em razão disso, há "reações" dos torcedores do time rival, o Feyenoord, quando os clubes se enfrentam. Cantos como "Hamas Hamas, judeus para o gás" e um sibilo "shhhhhh" (imitando uma câmara de gás) são comuns em jogos entre as duas equipes. (CARTA CAPITAL, 2009).

Outro caso similar envolveu o zagueiro croata JosipŠimunić, acusado de neonazismo após uma partida de sua seleção. Ao final do jogo, o atleta usou a saudação "Za dom” ("Para casa"), e os torcedores respondiam "Spremni” ("Pronto!"), fazendo referência a uma saudação fascista usada pelo croata Ustaše durante a Segunda Guerra Mundial. Em decorrência deste incidente, Šimunić foi multado por incitar o ódio racial e, após uma investigação, a FIFA decidiu também por suspender Šimunić por dez partidas oficiais, deixando-o fora da Copa do Mundo de 2014 no Brasil. (TERRA, 2013).

\subsubsection{Casos de racismo no futebol}

Além dos problemas de violência e xenofobia que ocorrem nos estádios de futebol ao redor do mundo, há ainda um outro grande problema que necessita ser combatido, que é o racismo, seja através de xingamentos ou sinais, praticado em razão de alguma partida de futebol, que ocorra dentro e fora de campo.

O livro "O Negro no Futebol Brasileiro", de Mário Rodrigues Filho (2003), foi pioneiro sobre relações étnico-raciais, no futebol brasileiro. Lançado, originalmente, em 
Campos Neutrais - Revista Latino-Americana de Relações Internacionais Vol. 2, No 1, Janeiro- Abril de 2020. Santa Vitória do Palmar - RS.

1947 e trata de questões, como a ascensão social do negro e seu reflexo no futebol, ocorrendo, assim, sua "provação" e sua "vez" na sociedade e no futebol. Dentre outras obras, observamos "A linguagem racista no futebol brasileiro" (da Silva, 1998), onde o autor interpreta notícias veiculadas em jornais, após as derrotas da seleção brasileira, em Copas do Mundo, discutindo sobre o papel da mídia na reprodução e construção do racismo no futebol brasileiro.

Muitos casos de racismo, no futebol, foram registrados ao longo da história. Alguns mais recentes tiveram grande repercussão na imprensa. Na Europa, dentre os mais falados foi o do atacante camaronês Samuel Eto'o, que, em fevereiro de 2005, sofreu abuso verbal por alguns torcedores do Real Zaragoza. Eto'o afirmou que ele não leva seus filhos a jogos de futebol, devido ao racismo existente nos estádios.

Já na América do Sul, a Copa Libertadores da América é alvo de grandes atos de racismo. Um deles envolveu o atacante brasileiro "Grafite" e o zagueiro argentino Leandro Desabato (ABRAHÃO; SOARES, 2007), preso por proferir ofensas racistas ao atleta brasileiro, em 14 de abril de 2005. Desabato foi mantido preso por 16 horas e libertado após o clube argentino pagar uma fiança de 10 mil reais. $\mathrm{O}$ caso recebeu uma grande cobertura da imprensa nacional e internacional.

Mais recentemente, no mesmo torneio, o meio-campo Tinga, do Cruzeiro, foi também alvo de racismo, em uma partida em Huancayo no Peru. O atleta ouvia provocações racistas a cada vez que tocava na bola. Após a partida, ele proferiu a seguinte frase: "Eu trocaria todos os meus títulos para o fim do preconceito". Apesar do fato, o árbitro não parou a partida, nem relatou o incidente na súmula. Ainda, para delegado da Conmenbol, Tinga não sofreu racismo. (TERRA, 2014):

Um moreno peruano imitando macaco para um brasileiro um pouco mais escuro do que ele não é discriminação racial. É sim uma provocação maleducada. (...) Não devemos reagir como os europeus. Somos filhos de uma mistura de brancos, índios e africanos. (...) Nós, os sul-americanos, não somos racistas. Somos sim o povo mais mal-educado do mundo. Nos falta até mesmo cultural para, filosoficamente falando, provocarmos discriminação racial. (...) Acredito que o tribunal vai analisar o nível da gravidade, mas com intenção de proferir uma pena didática, não muito radical.

\section{Lógica periferia-centro e a quebra de paradigmas com o futebol}

A partir do entendimento do pensamento pós-colonial, se observa o futebol como um ponto de referência para que se entendam problemas que ocorrem, cotidianamente, no 
Campos Neutrais - Revista Latino-Americana de Relações Internacionais Vol. 2, No 1, Janeiro- Abril de 2020. Santa Vitória do Palmar - RS.

mundo inteiro, e desta forma, busca-se, através dele, iniciar um processo de decolonização. Contudo, percebe-se que o futebol possui um grande potencial socializador, e já, hoje, quebra paradigmas impostos dentro do sistema-mundo moderno.

O processo de decolonização é interno, muitas vezes intersubjetivo, porém o esporte surge como uma maneira de ajudar, nesse processo. O futebol, por si só, já possui, para os sul-americanos, um sentimento decolonial, do "sul global" se tornar "norte global", devido à força de suas seleções e de seus clubes, em âmbito mundial. Esse fato foi de alta relevância no processo de decolonização e, inclusive, na própria autoestima de povos periféricos.

\subsection{Decolonialidade e futebol}

O sistema-mundo moderno, através de sua lógica neoliberal, é heterogêneo, em termos culturais, políticos e econômicos, possuindo grandes diferenças de desenvolvimento civilizacional, acumulação de capital e poder político. Immanuel Wallerstein (2005) atribui estas diferenças à própria natureza do sistema-mundo, pois é inerente ao sistema uma divisão entre centro, periferia e semiperiferia, em razão da divisão do trabalho entre as regiões.

Dentro da sistemática, o centro é a área de grande desenvolvimento tecnológico, sendo a periferia a área que fornece matérias-primas, produtos agrícolas e força de trabalho barata. Em razão disso, a troca econômica entre periferia e centro é desigual, já que a periferia tem de vender barato os seus produtos, enquanto compra caro os produtos do centro. Nesse sentido, o futebol mostra essa lógica através do seu mercado, o qual gira verdadeiras fortunas nos países de centro (e, muitas vezes, também nos de periferia). Grandes atletas de países periféricos ou do também chamado sul global, acabam indo jogar na Europa ou em países do norte global.

Contudo, mesmo o futebol reproduzindo esse sistema, ainda sim é um mecanismo de decolonialidade. A Federação Internacional de Futebol Associado (FIFA), entidade máxima do esporte, em conjunto instituições ligadas à Organização das Nações Unidas $(\mathrm{ONU})$ e seus programas, trabalham muito no combate à vários problemas enfrentados pela sociedade, os quais refletem-se também no futebol. No artigo $3^{\circ}$ do Estatuto da entidade, a FIFA (2013) reconhece a sua responsabilidade nos esforços para acabar com todas as formas de preconceito no futebol:

Luta contra a discriminação e postura contra o racismo: É proibida a 
discriminação contra qualquer país, indivíduo ou grupo de pessoas com base na raça, cor da pele, origem étnica, nacional ou social, sexo, língua, religião, posição política ou social. qualquer outra natureza, poder aquisitivo, naturalidade ou procedência, orientação sexual ou por qualquer outro motivo, e será punível com suspensão ou exclusão. (Tradução nossa) $)^{5}$

A FIFA possui 211 federações filiadas a ela, e usa a simbologia do futebol de maneira extremamente interessante. Possui programas, como o Fair Play (jogo limpo) e de combate à discriminação, principalmente ao racismo, no qual, em diversas ocasiões, nos momentos que antecedem partidas internacionais importantes, os capitães de cada equipe falam, em suas línguas, mensagens contra o racismo e toda e qualquer forma de discriminação.

Além disso, conflitos históricos de ordem econômica, política e religiosa são colocados de lado em partidas de futebol. Um claro exemplo foi na partida da Copa do Mundo de 1998, no confronto entre Estados Unidos e Irã, na primeira fase do campeonato mundial. Inimigos históricos, antes de iniciar a partida foram trocadas flores, entre os atletas, claramente como um símbolo de paz, entre as nações, pelo menos no campo de jogo. Essa atitude mostra que muitos, ainda, acreditam em um mundo melhor e com menos conflitos e diferenças.

Em relação ao racismo, um atleta negro foi considerado o melhor jogador de todos os tempos. O brasileiro Edson Arantes do Nascimento, conhecido, mundialmente, como Pelé, autor de mais de mil gols em sua carreira, tricampeão mundial de futebol pela seleção brasileira e bicampeão mundial de clubes pelo Santos, foi o vencedor de diversos prêmios, incluindo o de Atleta do Século, pelo jornal francês L'Equipe, no dia 12 de julho, de 1980. Em 2014, aos 73 anos de idade, recebeu o prêmio Bola de Ouro honorário da FIFA, tendo em vista que, durante sua carreira (de 1956 a 1977), o prêmio era dado apenas para jogadores que atuavam na Europa, com a clara visão eurocentrista do esporte.

\subsection{América do Sul e o norte global no futebol}

Nessa perspectiva, com o futebol reproduzindo a lógica colonial sob diversos aspectos, tendo o esporte ainda uma visão eurocentrista, o futebol quebra algumas barreiras. O esporte mundial é dividido em duas grandes potências: a Europa e a América do Sul. Apesar de gigantescas diferenças econômicas, com países de primeiro mundo

\footnotetext{
${ }^{5}$ Lucha contra la discriminación y postura contra el racismo: Está prohibida la discriminación de cualquier país, individuo o grupo de personas por cuestiones de raza, color de piel, su origen étnico, nacional o social, sexo, lengua, religión, posicionamiento político o de cualquier otra índole, poder adquisitivo, lugar de nacimiento o procedencia, orientación sexual o por cualquier otra razón, y será punible con suspensión o exclusión.
} 
Campos Neutrais - Revista Latino-Americana de Relações Internacionais Vol. 2, No 1, Janeiro- Abril de 2020. Santa Vitória do Palmar - RS.

(como os Estados Unidos) sendo equipes sem tradição, com nenhum título de expressão, as grandes seleções se concentram na Europa e na América do Sul.

Isso se mostra na expressão dos títulos conquistados por países dos continentes citados. A Copa do Mundo de seleções, disputada ${ }^{6}$, de 4 em 4 anos, desde 1930, possuiu vencedores, tanto sul-americanos, quanto europeus (Tabela 1).

TABELA 1 - Títulos referentes ao Copa do Mundo de seleções, desde 1930, conquistados por Sul-americanos e Europeus

\begin{tabular}{l|l|l|l}
\multicolumn{2}{l|}{ Sul-americanos } & Europeus & \\
\hline País & Campeonato conquistado & País & Campeonato conquistado \\
\hline Brasil & $1958,1962,1970,1994,2002$ & Itália & $1934,1938,1982,2006$ \\
\hline Uruguai & 1930,1950 & Alemanha & $1954,1974,1990,2014$ \\
\hline Argentina & 1978,1986 & França & 1998,2018 \\
\hline & & Inglaterra & 1966 \\
\hline & & Espanha & 2010 \\
\hline
\end{tabular}

FONTE: FIFA (2020)

Das 20 Copas do Mundo, disputadas até hoje, há 12 títulos de seleções europeias e nove títulos de seleções sul-americanas, percebe-se uma hegemonia desses dois continentes, ao longo de um século de história. Na lógica colonial é interessante perceber que, o Brasil, maior campeão de todos os tempos do esporte mais praticado do mundo possui cinco títulos, em contrapartida Portugal, país colonizador, nunca conquistou um título de expressão. Assim, nota-se que colônias espanholas, Argentina e Uruguai acumulam juntas quatro títulos mundiais, contra apenas um dos seus colonizadores espanhóis.

A hegemonia de ambos os continentes também se reflete nos campeonatos mundiais de clubes. Desde a chamada Copa Intercontinental, até depois chamada de Copa do Mundo de Clubes da FIFA $^{7}$ formam um total de 59 edições, com 26 conquistas de times sul-americanos e 33 conquistas de clubes europeus, mesmo com a diferença econômica gigantesca entre os grandes clubes da Europa (muitos com jogadores sul-americanos), em relação aos demais clubes do mundo. Dentre os clubes da América do Sul, que venceram o campeonato mundial de clubes, observamos, na tabela 2, argentinos, brasileiros, uruguaios e paraguaios.

\footnotetext{
${ }^{6}$ A Copa do Mundo de Futebol da FIFA não foi disputada apenas entre os anos de 1938 e 1950 , em virtude da $2^{\text {a }}$ Guerra Mundial. ${ }^{7}$ A chamada Copa Intercontinental foi disputada a partir de 1961 até o ano de 2004, sendo um confronto entre os clubes campeões da Copa dos Campeões da UEFA e da Libertadores da América. Depois disso a FIFA começou a organizar o mundial, transformando-o em um torneio com clubes campeões de todos os continentes. Teve uma edição no ano de 2000, contestada, mas a partir de 2005 consolidou-se.
} 
Campos Neutrais - Revista Latino-Americana de Relações Internacionais Vol. 2, No 1, Janeiro- Abril de 2020. Santa Vitória do Palmar - RS.

TABELA 2 - Equipes sul-americanas que conquistaram o Campeonato Mundial de Clubes.

\begin{tabular}{l|l}
\hline Equipe - Pais & Campeonato conquistado \\
\hline Peñarol-URU & $1961,1966,1982$ \\
\hline Nacional-URU & $1971,1980,1988$ \\
\hline Boca Juniors-ARG & $1977,2000,2003$ \\
\hline São Paulo-BRA & $1992,1993,2005$ \\
\hline Santos-BRA & 1962,1963 \\
\hline Independiente-ARG & 1973,1984 \\
\hline Independiente-ARG & 1973,1984 \\
\hline Corinthians-BRA & 2000,2012 \\
\hline Racing-ARG & 1967 \\
\hline Estudiantes de La Plata-ARG & 1968 \\
\hline Olimpia-PAR & 1979 \\
\hline Flamengo-BRA & 1981 \\
\hline Grêmio-BRA & 1983 \\
\hline River Plate-ARG & 1986 \\
\hline Vélez Sársfield-ARG & 1994 \\
\hline Internacional-BRA & 2006 \\
\hline FONTE: FIFA (2020) e Terra (2012b) &
\end{tabular}

No sorteio das chaves para a Copa do Mundo, de 2014 no Brasil, levou-se em conta o ranking da FIFA (2014b), na escolha dos chamados "cabeças de chave", visando trazer equilíbrio aos grupos. Acabaram participando 4 países sul-americanos (Brasil, Argentina, Uruguai e Colômbia) e 4 países europeus (Espanha, Alemanha, Bélgica e Suíça), o que reforça a hegemonia dos continentes. Quebra-se a lógica periferia-centro do sistemamundo moderno, colocando países de periferia no centro no mundo do futebol, ao mesmo tempo que se coloca grandes potências do centro como países periféricos. Na Copa do Mundo de 2018, o Ranking da FIFA apontava entre as 10 primeiras seleções 4 sulamericanas e 6 europeias.

\section{Conclusão ou Considerações}

Através de um breve diálogo sobre a temática decolonial e pós-colonial, passando pelo entendimento da lógica da modernidade e colonialidade, assim como pela teoria do sistema-mundo moderno, de Wallerstein (2005), chega-se à conclusão da necessidade de mecanismos que buscam a decolonialidade, enraizada nos chamados subalternos.

O futebol se torna um importante objeto de análise, sendo uma questão passível de estudo. Demandas reivindicadas na sociedade são postas em xeque, em jogos de futebol, dentro e fora dos estádios. Problemas como o racismo, a violência e a xenofobia são, infelizmente, recorrentes no esporte. Porém, são apenas reflexos dessa sociedade, uma ilustração das condutas (i)morais do cidadão, as quais, na grande maioria das vezes, são 
Campos Neutrais - Revista Latino-Americana de Relações Internacionais Vol. 2, No 1, Janeiro- Abril de 2020. Santa Vitória do Palmar - RS.

reflexo de séculos de exploração por elites coloniais, reproduzidas até hoje.

Após a citação de algumas entre as centenas de casos que ocorreram em estádios, é possível notar que o futebol é extremamente importante nesse processo colonial. O próprio futebol é um mecanismo de combates a esses problemas, com diversas campanhas pelo fim do preconceito em toda sociedade. Além disso, é um esporte capaz de quebrar, talvez de maneira única, a ideia de periferia-centro, do sistema-mundo moderno.

Mesmo com a desigualdade econômica, a mercantilização de atletas para países do norte global, a América do Sul é, juntamente com a Europa, o centro do futebol no mundo. Assim, seleções nacionais, como clubes sul-americanos, são campeões do mundo, disputando sempre com europeus a hegemonia do futebol mundial. Essa importância é sem precedentes, inclusive para a autoestima de povos colonizados e escravizados por séculos, que ainda hoje possuem o chamado "complexo de vira-lata" 8 .

Fica claro, principalmente na ótica do Brasil, o sentimento que se teve, após a derrota da seleção na final da Copa do Mundo de 1950, quando se teve a impressão de que nada nesse país daria certo. Exatamente essa era o pensamento colonial que se reproduzia, o qual, hoje, foi quebrado pelo futebol, sendo o Brasil o maior vencedor de todos os tempos e servindo de modelo para o mundo inteiro.

\section{Bibliografia}

ABRAHÃO, B. O. de L.; SOARES, A. J. Uma análise sobre o caso 'Grafite X Desábato' à luz do 'racismo à brasileira'. Esporte e Sociedade. Ano 2, n.5, Rio de Janeiro. Universidade Federal do Rio de Janeiro. 2007.

BALLESTRIN, L. América Latina e o giro decolonial. Revista Brasileira de Ciência Política. n.11, 2013. pp. 89-117.

CARTA CAPITAL. Torcidas organizadas: o exemplo que vem da Holanda. São Paulo. 2009. Disponível em: <http://esportefino.cartacapital.com.br/torcidas-organizadas-o-exemplo-que-vemda-holanda/> Acesso em 20 mar. 2014.

CASTRO-GÓMES, S. La Poscolonialidad explicada a los niños. Bogotá: Universidad del Cauca y Instituto Pensar. 2005.

DA SILVA, C. A. F. A linguagem racista no futebol brasileiro. In: Congresso Brasileiro de História do Esporte, Lazer e Educação Física. 6, 1998. Rio de Janeiro. Anais do VI Congresso Brasileiro de História do Esporte, Lazer e Educação Física, Rio de Janeiro: Editora Central da Universidade Gama Filho, IHGB, INDESP, 1998. p. 394-406.

DUSSEL, E.Hacia una filosofia política crítica. Bilbao: Desclée. 2011.

FIFA. Estatutos de la FIFA. Zurique. 2013. Disponível em:

\footnotetext{
8 "Complexo de vira-lata" é uma expressão criada pelo escritor brasileiro Nelson Rodrigues. Originou-se na derrota em casa da Seleção Brasileira para o Uruguai na final da Copa de 1950. Para o escritor, o fenômeno não se limitava ao futebolístico, entendendo esse "complexo" como a inferioridade em que o brasileiro se colocava, voluntariamente, em face do resto do mundo, cuspindo na própria imagem.
} 
Campos Neutrais - Revista Latino-Americana de Relações Internacionais Vol. 2, No 1, Janeiro- Abril de 2020. Santa Vitória do Palmar - RS.

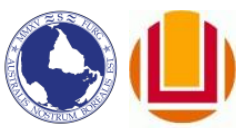

<http://www.fifa.com/mm/document/AFFederation/Generic/02/14/97/88/FIFAStatuten2013_S_Sp anish.pdf> Acesso em 24 mar. 2014.

Copa do Mundo da FIFA. Zurique. 2014. Disponível em: <http://pt.fifa.com/tournaments/archive/worldcup/index.html> Acesso em 10 mar. 2014.

Copa do Mundo de Clubes da FIFA. Zurique. 2014a. Disponível em: <http://pt.fifa.com/tournaments/archive/clubworldcup/index.html > Acesso em 10 mar. 2014.

Ranking mundial da FIFA. Zurique. 2014b. Disponível em: <http://pt.fifa.com/worldranking/rankingtable/> Acesso em 11 mar. 2014.

FANON, F. Os condenados da Terra. Trad. José Lourênio de Melo. Rio de Janeiro: Civilização Brasileira. 1968.

FOLHA DE SÃO PAULO. Unicef faz campanha antidiscriminação. São Paulo. 2011. Disponível em: <http://www1.folha.uol.com.br/fsp/esporte/fk0307201109.htm> Acesso em 22 de jun. 2020.

GONZÁLEZ CASANOVA, P.Colonialismo interno (uma redefinição). Enpublicacion: A teoria marxista hoje. Problemas e perspectivas. Boron, A. A.; Amadeo, J. y Gonzalez, S. 2007.

IG. Federação Boliviana protesta contra atos xenófobos no Clausura. São Paulo. 2009. Disponível em: <http://esporte.ig.com.br/futebol/2009/03/11/federacao+boliviana+protesta+contra+atos+xenofobo s+no+clausura+4691941.html> Acesso em 22 de jun. 2020.

LANCENET. Inglaterra precisou de duas tragédias para combater a violência no futebol. Rio de Janeiro. 2013. Disponível em: <http://www.lancenet.com.br/minuto/Inglaterra-precisoutragedias-combater-violencia_0_1044495718.html> Acesso em 20 de mar. 2014.

MANIFESTO INAUGURAL. Grupo Latinoamericano de Estudios Subalternos. In: Castro-Gómez, S. y Mendieta, E. (orgs). Teorías sin disciplina: latinoamericanismo, poscolonialidad y globalización en debate. México: Miguel Ángel Porrúa. 1998.

MIGNOLO, W. La idea de América Latina: la herida colonial y la opción decolonial. Barcelona, Gedisa Editorial. 2005.

Thedarkersideof Western modernity: global futures, decolonial options. Durham: Duke UniversityPress, 2011.

Epistemic disobedience. Rhetoric of modernity, logic of coloniality and decolonial grammar. Ediciones Del Signo, Buenos Aires, 2010.

MSN. Em jogo marcado por xenofobia, Vélez vence Boca e assume a liderança na Argentina. São Paulo. 2014. Disponível em: <http://esportes.br.msn.com/futebol/em-jogo-marcado-porxenofobia-v\%C3\%A9lez-vence-boca-e-assume-a-lideran\%C3\%A7a-na-argentina-1> Acesso em 22 de mar. 2014.

QUIJANO, A. Colonialidad y Modernidad-racionalidad. In: Bonillo, H. (comp.). Losconquistados. Bogotá: Tercer Mundo Ediciones; FLACSO. 1992.

. Colonialidade do poder, eurocentrismo e América Latina. In: LANDER, Edgardo (org). A colonialidade do saber: eurocentrismo e ciências sociais, perspectivas latino-americanas. Buenos Aires: Clacso, 2005.

RESTREPO, E.; ROJAS, A. Inflexión decolonial, Popayán, Colombia, Universidad del Cauca, Instituto Pensar, Universidad Javeriana.2010.

RODRIGUES FILHO, M. O negro no futebol brasileiro. 4. ed. Rio de Janeiro:Mauad, 2003.

TERRA. Fifa divulga novo ranking e confirma cabeças-de-chave da Copa. São Paulo, 2012. Disponível em: <http://esportes.terra.com.br/futebol/copa-2014/fifa-divulga-novo-ranking-econfirma-cabecas-de-chave-da-copa- 
Campos Neutrais - Revista Latino-Americana de Relações Internacionais Vol. 2, No 1, Janeiro- Abril de 2020. Santa Vitória do Palmar - RS.

veja,b97e28e41e5c1410VgnVCM20000099cceb0aRCRD.html>. Acesso em: 10 mar. 2014.

Incidentes do confronto entre Polônia e Rússia pela Euro deixaram 184 detidos e 20

feridos. São Paulo. 2012a. Disponível em: <http://esporte.uol.com.br/ultimasnoticias/afp/2012/06/13/incidentes-de-polonia-russia-deixaram-184-detidos-e-20-feridos.htm> Acesso em 22 jun. 2020.

Mundial de Clubes. São Paulo, 2012b. Disponível em:

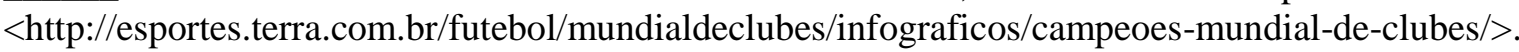
Acesso em: 10 jun. 2020.

Fifa confirma punição e tira croata da Copa por fascismo. São Paulo. 2013. Disponível em: $\quad$ http://esportes.terra.com.br/futebol/fifa-confirma-punicao-e-tira-croata-da-copa-porfascismo,e918dca172cd4410VgnCLD2000000dc6eb0aRCRD.html> Acesso em 20 jun. 2020.

Cartola argentino nega racismo com Tinga: foi provocação. São Paulo. 2014. Disponível em: <http://esportes.terra.com.br/futebol/secretario-geral-da-conmebol-minimizaagressoes-racistas-a-tinga,9d3825e12f4e4410VgnCLD2000000dc6eb0aRCRD.html> Acesso em 22 jun. 2020.

WALLERSTEIN, I. Análisis de sistemas-mundo: una introducción. México: Siglo XXI Editores. 2005. 